EDITORIAL

\title{
Tempos diferentes
}

Cândido Alberto Gomes ${ }^{a}$

O número 110 da Ensaio: Avaliação e Políticas Públicas em Educação surge em tempo diverso, em que se trata de "normal" e de "novo normal", sem definir exatamente o que significam. São tempos de pandemia, em que a sociedade e a economia, como a Educação se transformam. Trata-se do futuro do trabalho, da "nova" robotização e da inteligência artificial, mudanças apressadas, rimando (rima pobre) com sofisticadas, embora nos faltem tempo e inteligência para melhor compreender um vírus, que nem é um ser vivo. Escolas abrem-se, encerram-se, reabrem-se, recorrem às tecnologias num mundo que, subitamente, se tornou mais desigual, a desafiar ainda mais a concretização dos direitos humanos.

Modos de vida mudaram para o relativo confinamento, sem contatos pessoais. Proibir crianças e adolescentes de se abraçarem e se beijarem depois de longo tempo de ausência pode ser correto, porém dificilmente é viável. Isolados, cabe lembrar sensações de Anne Frank (2015), refugiada no Anexo Secreto. No florescer da sua autoescrita, endereça-se à amiga imaginária:

Sem dúvida, você quer saber o que acho de estar escondida. Bom, só posso dizer que ainda não sei direito. Acho que nunca me sentirei à vontade nesta casa, mas isso não significa que eu a odeie. É como estar de férias em alguma pensão estranha. É um modo meio diferente de encarar a vida num esconderijo, mas é assim que as coisas são (p. 48).

O mundo hoje, lamentavelmente, revive muros, fronteiras fechadas, descrença na democracia, culto a homens todo-poderosos, extremismos político-religiosos, racismo e xenofobia, olvidando experiências anteriores. Mais ainda, a pandemia nos leva a um "meio diferente de encarar a vida" no encapsulamento, para evitar o pior. Contudo, no confinamento, Anne amadureceu, guardou a esperança e foi capaz de se comover, junto ao seu futuro primeiro amor, com a beleza lá de fora:

Vou ao sótão quase todas as manhãs... [...] [Peter] estava fazendo a limpeza. Ele terminou depressa e veio até onde eu estava, meu local preferido no chão. Nós dois olhamos para o céu azul, para

\footnotetext{
a Instituto de Estudos Superiores de Fafe, Fafe, Medelo, Portugal.
} 
o castanheiro nu brilhando de umidade, as gaivotas e outras aves luzindo de prata, enquanto rodopiavam no ar, e ficamos tão comovidos e extasiados que não conseguíamos falar. [...]

O melhor remédio para os amedrontados, solitários ou infelizes é sair, ir a um local em que possam ficar a sós, com o céu, a natureza e Deus. [...]

\begin{abstract}
Ah, quem sabe, talvez não demore muito antes que eu possa compartilhar esse sentimento de felicidade avassaladora com alguém que sinta o mesmo que eu (p. 243-244).
\end{abstract}

Não nos encontramos numa guerra, como Anne e os seus, embora também nos recolhamos para assegurar a continuidade da vida. Ela viveu parte da adolescência pelo avesso, sem grupos de colegas, sem as amigas e os "admiradores" de antes, exposta às críticas de adultos. Crianças e jovens hoje vivem o confinamento, também com o desenvolvimento parcial da sua socialização. Ainda assim, é preciso discernir lá fora o bom, o belo e o verdadeiro e sentir o sopro da esperança. Apesar da pandemia e das sombras da História, o pensamento e a razão persistem e talvez se encontrem ainda mais ativos nas ciências, sobretudo nas ciências da vida. Também na arte não se parou de sentir e pensar, interpretando a fragilidade do mundo e do ser humano, de modo que podemos esperar obras de arte capazes de expressar em volumes, linhas, cores, sons e palavras as novas dimensões dos fatos. E a filosofia, permeando tudo isso, continua a refletir sobre os significados da vida fugidia.

Assim, este alentado número 110 da Ensaio é uma evidência do pensamento, da criação e da reflexão não interrompidos, tal qual o perpétuo fluir do tempo. Já que a Revista não publica números monotemáticos, neste desfolhar de exposição e de comentários ao seu conteúdo, divisamos a convergência para artigos sobre a avaliação de escolas e de programas.

A presente caminhada começa com um artigo sobre o êxito/insucesso discente em algumas redes escolares do Brasil, com os dados do Pisa 2019. Ao cotejar escolas diferentes, em "O que o Pisa para escolas revela sobre uma rede de ensino no Brasil?", Nilma Fontanive, Ruben Klein, Suely Rodrigues e Alice Moraes constatam os inevitáveis efeitos de variáveis extraescolares, embora avancem na investigação de fatores intraescolares de grande relevância, como o bullying e os procedimentos didáticos.

Segue-se um artigo basilar, na perspectiva humanista, "Formação de professores e currículo: questão em debate", de Antonio Flávio B. Moreira. Trata-se da análise 
teórica da formação inicial docente, a conceber o professor como intelectual formado para a autonomia e o pensamento crítico. Mais que oportuno quando tantos professores no mundo são rebaixados a técnicos, a selecionar "pacotes" transnacionais para seus alunos, todos "à prova de professor", em que até a avaliação vem pronta, mesmo que se choquem com a realidade vivida pelos discentes, captada pelos docentes. Esta tendência já se manifestava antes da pandemia e agravou-se com ela.

Em prosseguimento, vem um artigo da Europa Central sobre os direitos e deveres em face da Educação na Hungria, por Ákos Csermy e João Casqueira Cardoso. Sabemos que o país se tornou democrático e parlamentarista em 1989 e foi admitido à União Europeia em 2004. Neste período, democratizante emergiram as medidas e as instituições protetivas do direito à Educação. Outro país da União, a Espanha, é focalizado a seguir por Donaldo B. Souza, em "Planejamento: Planos de Educação na Espanha: evolução da produção acadêmica e científica 1978-2016". O autor analisou, em documentos do período de quase 40 anos, os compassos de mudança da política e da recepção de regulações supranacionais, isto é, comunitárias. 1978 foi o ano da Constituição democrática e parlamentarista. 1985, por sua vez, foi o ano da admissão à União Europeia. No sistema bipartidário, sucederam-se no poder o Partido Socialista Operário Espanhol e o Partido Popular. Novos partidos surgiram, em especial durante a grande recessão de 2008 em diante, mudando o panorama político.

O artigo seguinte é sobre Portugal, vizinho ibérico: “A figura do 'amigo crítico' no desenvolvimento de culturas de autoavaliação e melhoria de escolas", de Carlinda Leite e Paulo Marinho. Focaliza três escolas básicas cuja autoavaliação se fez apoiada por um assessor externo, o "amigo crítico", bem diferente dos hierárquicos inspetores, supervisores (os que olham de cima) ou avaliadores externos, com as mãos usualmente cheias de sanções. A pesquisa mostra a orientação horizontal da autoavaliação, com as vistas do que Simmel chama de "estrangeiro ou estranho sociológico". Quem vem de fora traz outros olhos, diferentes daqueles imersos na realidade escolar, como peixes dentro do rio.

Em coerência com os tempos hoje vividos, "Retention in MOOCs: some key factors", de Andrés Chiappe e Blanca D. Lorena Castillo, da Colômbia. A revisão de 113 artigos dirige a luz a um problema estratégico, a retenção/evasão discente na Educação a distância. Ricardo Marín, um dos fundadores da Universidad Nacional de Educación a Distancia, da Espanha, alertava para este ponto fulcral, integrante da qualidade e da atratividade, em suas viagens ao Brasil e aos brasileiros que recebia carinhosamente em seu país.

Daí se passa à socialização do estudante universitário em novos ambientes socioculturais, vindo da escola secundária, como tão bem analisou Coulon. 
Wagner B. Andriola e Adriana C. Araújo, em "Adaptação de alunos ao ambiente universitário: estudo de caso em cursos de graduação da Universidade Federal do Ceará", comparam gêneros feminino e masculino, cursos diurnos e noturnos, estudantes que trabalham ou não e cotistas e não cotistas. Os resultados se revestem de importância, sobretudo para a gestão universitária e apontam para uma dinâmica fadada a manter as desigualdades entre os gêneros.

O trabalho seguinte também tangencia as diferenças de gênero e os persistentes currículos "azuis" e "rosas", segundo Baudelot e Establet. Ramón García-Perales, Carmen Jiménez-Fernández e Ascensión Palomares-Ruiz, da Espanha, nos apresentam "Elecciones académicas e interés vocacional en alumnado com alta capacidad matemática". Verificando escolhas acadêmicas e interesse vocacional de 22 estudantes em dois momentos da sua carreira, constataram que as jovens, mesmo com reconhecida capacidade matemática, tenderam a não escolher cursos de ciências e tecnologias, com raízes na socialização feminina.

A seguir vem "O programa Ciência sem Fronteiras", de Cintia D. Granja e Ana Maria Carneiro, avaliação do programa governamental brasileiro, sob a ótica do ciclo de políticas públicas. As conclusões devem ser anotadas para outros casos em que se pode atropelar a realidade com tempos e objetivos políticos atuantes no teatro político, que só funciona como tal quando, na ingenuidade, não percebemos as ações teatrais no âmbito das sociedades do espetáculo.

Em continuidade, outro artigo de avaliação, "Avaliação de desempenho para o apoio à Gestão de Unidades Organizacionais em Ifes" (Instituições Federais de Educação Superior), por Tatiane R. Bastos, André A. Longaray Aléssio B. Sarquis e Vilmar A. G. Tondolo. Compreende uma visão sistemática da literatura para fundamentar a gestão de universidades públicas, com abordagem construtivista.

"A importância da Educação Superior na redução das disparidades de renda em Santa Catarina", por Amanda M. Silva, Mário C. B. Moraes, Sulivan D. Fischer e Claúdia M. Gribosky, mostra as desigualdades encobertas por elevados índices de desenvolvimento humano. $\mathrm{O}$ artigo assinala o aumento das diferenças salariais entre os que concluíram o Ensino Médio e a Educação Superior, com os dados da Rais, isto é, de empregados do setor formal. Os dados estatísticos e os candentes mapas indicam o alto retorno individual dos cursos superiores para os que o completam, ao contrário de um elenco de outros países.

No encerramento do presente número, em "Página Aberta”, María E. Unriza Puin, Isabel Hernández Arteaga e Fredys A. Simanca nos brindam com "Percepciones 
de los docentes universitários para la construcción de uma cultura de paz”. A investigação qualitativa aborda o delicado processo de paz dos nossos vizinhos colombianos. Este processo, em várias etapas e tentativas, começa nos anos $1980 \mathrm{e}$ estende-se à segunda década deste século. Os docentes de nível superior convergiram no sentido da falta de confiança no processo de pacificação, por falta de clareza, grande número de inimigos e por os principais atores darem as costas à democracia.

Esta sucessão de trabalhos deixa claro que a pesquisa e a disseminação não cessaram nos novos tempos, talvez até hajam se acelerado. A articulação de talentos e saberes, o longo número de dias e de horas dedicados ao trabalho de criar ratificam que o confinamento não é necessariamente um estado de regressão e de isolamento. Para o bem e para o mal, as tecnologias têm facilitado a dinâmica das sociedades em rede. Como Anne no Anexo Secreto, é preciso fazer luzir a virtude da esperança. Anne, por pouco tempo, não pode regressar fisicamente, porém a sua presença está entre nós até hoje, a tocar coração e mentes de adolescentes, de jovens e de adultos, quer socialmente favorecidos, quer desfavorecidos, nas periferias. O "Diário", assim patenteia a interculturalidade de sentimentos comuns, expressos em quase 70 idiomas. Isto significa que tais emoções e pensamentos fazem parte não de apenas algumas culturas ou tempos de guerra, mas da civilização que as enlaça e entrelaça na riqueza da pluralidade, em lugar da pobreza da singularidade (MORIN, 2001).

\section{Referências}

FRANK, A. O diário de Anne Frank. 49. ed. Rio de Janeiro: Record, 2015.

MORIN, E. Os sete saberes necessários à Educação do futuro. São Paulo: Cortez; Brasília, DF: UNESCO, 2001.

\section{Informações sobre o autor}

Cândido Alberto Gomes: Doutor em Educação pela Universidade da Califórnia, Los Angeles. Professor Catedrático e Diretor do Centro de Investigação do Instituto Superior de Estudos de Fafe, Portugal. Assessor Legislativo selecionado por concurso público, reformado, do Senado Federal e da Assembleia Nacional Constituinte. Contato: candidoacg@gmail.com

iD http://orcid.org/0000-0001-8498-3785 